\title{
Pequeno guia/vocabulário para a utilização da história arqueológica como instrumento de pesquisa qualitativa
}

A small guidelglossary for the use of archeological history as a qualitative research instrument

Everardo Duarte Nunes ${ }^{1}$

${ }^{2}$ A abreviatura Arq. será usada para referência à Arqueologia do Saber, tradução de Luiz Felipe Baeta Neves.

Petrópolis: Vozes, Lisboa: Centro do Livro Brasileiro, 1972, acrescida do número da página a que se refere.

\section{Introdução}

Sob muitos aspectos pode ser analisada a obra de Michel Foucault. A riqueza da temática de seus trabalhos e a forma original sob a qual foi abordada constituem uma enorme fonte de contribuições, comentários e críticas. Avaliar os instrumentos conceituais, teóricos e metodológicos também tem sido a proposta de alguns estudiosos, como Machado (1981), sobre a Arqueologia, Almeida (1994), ao se voltar para a questão do problema da genealogia, Rabinow \& Dreyfuss (1995) sobre a trajetória filosófica de Foucault.

De outro lado, a história arqueológica, desde o momento em que Foucault terminou seu terceiro trabalho nesta linha, Les Mots et les Choses (1966), antecedido pela História da Loucura (1961) e o Nascimento da Clínica (1963), foi alvo de muitos ensaios. Em 1969, Foucault publicaria L'archeologie du Savoir e o próprio autor, antecipando-se aos críticos e depois de assinalar que o livro "não é a retomada e a descrição exata do que se pode ler na Histoire de la Folie, na Naissance de la Clinique ou em Les Mots et les Choses. Em muitos pontos é diferente" (Arq., p.25)², faz uma série de questionamentos sobre o fato de que os críticos iriam perguntar se ele estaria seguro ou não do que disse, se não iria deslocar-se em relação às questões que lhe eram feitas, que estaria arranjando saídas etc. A isso tudo, Foucault irá responder de uma maneira que se tornou clássica para situar a relação autor/obra: "Mais de um, como eu sem dúvida, escreveu para não ter mais fisionomia. Não me pergunte quem sou eu e não me diga para permanecer o mesmo: é uma moral de estado civil; ela rege nossos papéis. Que ela nos deixe livres quando se trata de escrever" (Arq., p.27).

Não pretendemos neste texto trabalhar as obras de Foucault, ou mesmo

${ }^{1}$ Departamento de Medicina Preventiva e Social, Faculdade de Ciências Médicas, Universidade de Campinas/UNICAMP. <evernunes@uol.com.br> 
estabelecer uma análise crítica sobre as suas contribuições, em especial aquelas que se dedicaram ao campo da Medicina, mas destacar aqueles aspectos que dizem respeito a sua Arqueologia e como ele procurou encaminhar a exposição dessa metodologia.

\section{Aspectos gerais do livro}

Em 1969, Foucault, que estava com 43 anos e "Aureolado pela glória que Ihe valeu Les Mots et les Choses", como diz seu biógrafo Didier Eribon (1990, p.175), escreve e publica Archéologie du Savoir. Ainda segundo Eribon (1990, p.178), "Ele escreve com ardor e se debate como um demônio em meio a noções de enunciado, formação discursiva, regularidade e estratégia. Todo um vocabulário que tenta estabelecer e fixar; todo um jogo de conceitos que se esforça para definir e articular".

É interessante e oportuno que se transcreva o próprio texto no qual Foucault, dono de uma linguagem inigualável, registra porque escreveu esse livro:

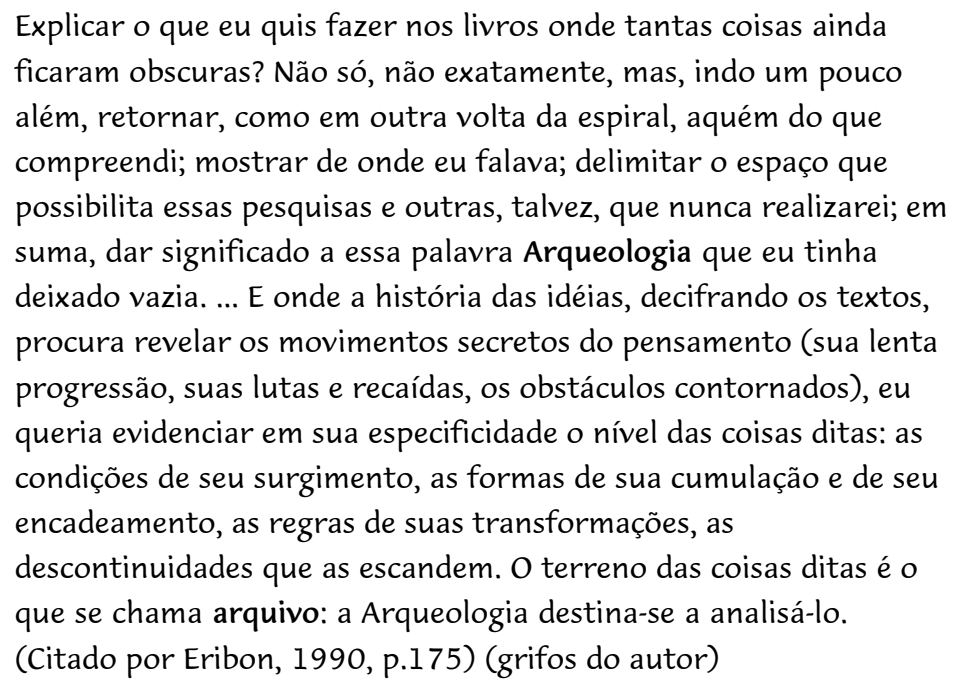

Não se trata de um trabalho estritamente metodológico, no sentido restrito de fornecimento de uma instrumentalização para as pesquisas das formações discursivas, mas encerra a proposta de explicar a conformação teórica do próprio projeto arqueológico. Ao introduzir o leitor nesse caminho, nas páginas iniciais do livro estabelece de que história ele irá tratar. A preocupação não será com "as vastas unidades que se descreviam como épocas ou séculos (mas) para fenômenos de ruptura” (Arq., p.10).

Para isso, busca em estudos precedentes de Bachelard e de Canguilhem, respectivamente, as noções de atos e limiares epistemológicos e deslocamentos e transformações dos conceitos. Em seguida, lembra-nos que há redistribuições recorrentes - a ciência sendo reescrita não mediante um 


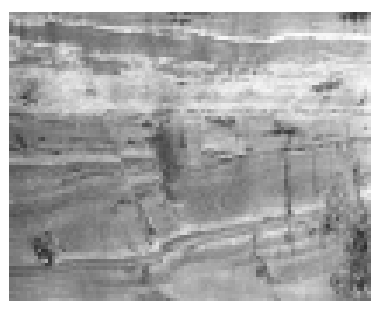

único passado, mas numa composição de encadeamentos, multiplicando-se em suas transformações; unidades arquitetônicas - em que o que se busca é a construção de sistemas nos quais são pertinentes os axiomas, as cadeias dedutivas, as compatibilidades; escansões - cortes que marcam quando se funda uma ciência destacando-a da ideologia. Estas idéias aparecem na Introdução, na qual o autor irá enfatizar pontos teóricos importantes do projeto. Acrescenta que na base da proposta está a crítica do documento e, no momento em que a história mudou sua maneira de enfrentá-lo, sua tarefa não será de interpretá-lo, "mas sim trabalhá-lo no interior e elaborálo: ela o organiza, recorta-o, distribui-o, ordena-o, reparte-o em níveis, estabelece séries, distingue o que é pertinente do que não é, delimita elementos, define unidades, descreve relações" (Arq., p.13). Se a história, em sua forma tradicional, pretendia memorizar os monumentos do passado, transformando-os em documentos, a história arqueológica transforma os documentos em monumentos.

Três outros pontos não podem deixar de ser citados, pois, quando a história se volta para a descrição intrínseca do documento, três conseqüências aparecem:

a multiplicação das rupturas e não mais o problema de constituir longos períodos, mas de séries, séries de séries (a dúvida da totalização), a individualização de séries, a não linearidade;

a noção de descontinuidade, não como o estigma da dispersão, mas como um instrumento e objeto de pesquisa;

o esboço de uma história geral e não de uma história global, que particulariza e redefine o espaço da historicidade e rompe com o princípio da coesão.

No plano do livro, suas unidades discursivas se distribuem, após a Introdução, em três partes: As regularidades discursivas; $O$ enunciado e o arquivo; A descrição arqueológica e Conclusão.

No plano desta tentativa de sintetizar o vocabulário e os elementos constitutivos de uma prática de investigação que utilize a análise de discurso, como parte integrante e central do campo da história arqueológica, apresentaremos, inicialmente, algumas definições. Estas são precedidas por quatro pressupostos que marcam e resumem o exposto acima. Para a história arqueológica, $e$ isto se aplica a qualquer objeto de discurso, os pressupostos são os seguintes:

libertar-se do tema da continuidade histórica, da noção de tradição, de influência, de desenvolvimento e evolução, de mentalidade ou espírito de uma época;

inquietar-se diante de certos recortes ou grupamentos que distinguem tipos, formas e gêneros de discursos, tais como os da ciência, da literatura, da filosofia, das artes etc.;

pôr em suspenso as unidades que se definem como livro e obra.

\section{Conceitos}

A quantidade de expressões e conceitos utilizados por Foucault é enorme e, muitas vezes, com diferentes significados. Isto dificulta organizar um vocabulário detalhado sobre a história arqueológica. Tentamos situar 
aqueles que são fundamentais e que não podem ser marginalizados em pesquisas que pretendam utilizar o enfoque arqueológico da análise do discurso.

\section{ENUNCIADO}

A unidade do discurso é o enunciado. Foucault distingue o enunciado da proposição dos lógicos, da frase dos gramáticos, do speech act dos analistas. Tece extensos argumentos para diferenciá-lo dessas categorias $e$ conclui: ele não é em si mesmo uma unidade, mas uma função que cruza um domínio de estrutura de unidades possíveis e que as faz aparecer, com conteúdos concretos, no tempo e no espaço. Apresenta-o como

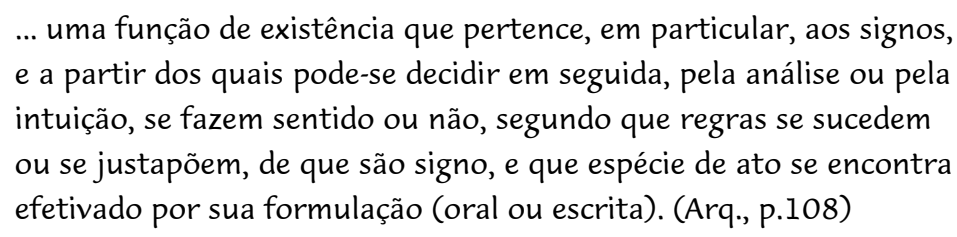

\section{FUNÇÃO ENUNCIATIVA}

Foucault não apresenta uma definição da função enunciativa, mas uma série de características (Arq., p.110-32). Sinteticamente:

O nível enunciativo de uma formulação "não se pode fazer nem por uma análise formal, nem por uma investigação semântica, nem por uma verificação, mas pela análise das relações entre o enunciado e os espaços de diferenciação, em que ele mesmo faz aparecer as diferenças"(Arq., p.115).

Como o sujeito do enunciado não necessita ser concebido como idêntico ao autor da formulação, "Descrever uma formulação enquanto enunciado não consiste em analisar as relações entre o autor e o que ele diz (ou quis dizer, ou disse sem querer), mas em determinar qual é a posição que pode ou deve ocupar todo indivíduo para ser o seu sujeito" (Arq., p.119-20).

A função enunciativa não pode se exercer sem a existência de um domínio associado. É este campo associado que torna uma frase ou uma série de signos um enunciado. Assim, o enunciado se inscreve no interior de uma série de outras formulações e se torna um elemento; repetindo, modificando ou adaptando formulações; possibilitando sua seqüência ou sua réplica, seu desaparecimento ou sua valorização para um discurso futuro.

O enunciado deve ter existência material. "O enunciado é sempre dado através de uma espessura material, mesmo se ela está dissimulada, mesmo se, apenas surgida, está condenada a desvanecer" (Arq., p.125).

\section{ARQUIVO}

Sendo a proposta foucaultiana a de estudar a existência dos acontecimentos discursivos (sistemas de enunciados) de uma cultura, propõe que a esses sistemas se denominem de arquivo (Arq., p.160). "O arquivo é, de início, a lei do que pode ser dito, o sistema que rege o aparecimento dos enunciados como acontecimentos singulares (Arq., p.161). É o sistema geral da formação e da transformação dos enunciados” (Arq., p.162). 
DISCURSO

Conjunto de enunciados que provêm de um mesmo sistema de formação, ou seja, que provêm da mesma formação discursiva.

\section{FORMAÇÃO DISCURSIVA}

Conjunto formado por um certo número de enunciados, conceitos, escolhas temáticas, que descreve sistemas de dispersões e busca verificar como o discurso se organiza em uma ordem, quais as correlações, as posições, os funcionamentos, as transformações (Arq., p.51).

\section{ANÁLISE DA FORMAÇÃO DISCURSIVA}

Para a análise da formação discursiva, Foucault introduz quatro categorias descritivas: os objetos, os sujeitos, a formação das modalidades discursivas, as estratégias. É a forma de descrever sistematicamente os acontecimentos discursivos procurando encontrar as unidades existentes.

\section{FORMAÇÃO DOS OBJETOS}

A formação dos objetos é atravessada por quatro momentos que levam o pesquisador a interrogar:

Quais são as superfícies primeiras de emergência desses objetos? Elas precisam ser demarcadas a fim de mostrar onde podem surgir, para que possam em seguida ser designadas e analisadas, segundo determinadas teorias, códigos etc. Trazer à tona aquilo de que se fala, dar-lhe o estatuto de objeto, torná-lo nomeável (Arq., p.55).

Quais são as instâncias institucionais que delimitam o objeto? (Arq., p.56)

Quais são os sistemas que separam, reagrupam, classificam, aproximam, derivam o objeto, estabelecendo grades de especificação? (Arq., p.56)

Para o autor, as condições que permitem que apareça um objeto de discurso e dele se fale é produto de um "feixe completo de relações". Estas se apresentam sob três modalidades:

relações primárias: são reais, não estão presentes no objeto; são estabelecidas entre instituições, processos econômicos e sociais, formas de comportamento, sistemas de normas, técnicas, topos de classificação, modos de caracterização (Arq., p.59-60).

relações secundárias: são reflexivas, formadas no interior do próprio discurso (Arq., p.60).

relações discursivas: não são nem internas nem externas ao discurso; estão no limite do discurso, determinam o feixe de relações que o discurso deve efetuar para poder falar dos objetos, tratá-los, nomeá-los, analisá-los, classificá-los, explicá-los. É "o próprio discurso enquanto prática” (Arq., p.61).

\section{FORMAÇÃO DAS MODALIDADES ENUNCIATIVAS}

Este nível comporta a descrição das formas dos enunciados, ou seja, estabelecer as relações do sujeito que enuncia. Para tal, é necessário que se respondam às seguintes questões:

Quem fala? Quem, no conjunto de todos os indivíduos-que-falam, está 
autorizado a ter esta espécie de linguagem? Quem é seu titular? Quem recebe dele esta singularidade, seus encantos, e de quem, em troca, recebe, senão sua garantia, pelo menos a presunção de que é verdadeira? Qual o estatuto dos indivíduos que têm - e apenas eles - o direito regulamentar ou tradicional, juridicamente definido ou espontaneamente aceito, de proferir semelhante discurso? (Arq., p.65).

De que lugares institucionais procedem os discursos? De onde o sujeito obtém seu discurso? (Arq., p.66).

Quais as posições do sujeito frente aos diversos domínios ou objetos? É sujeito-que-questiona? É sujeito que observa? O sujeito utiliza intermediários instrumentais? Que posições o sujeito ocupa na rede de informações, no campo dos domínios teóricos e institucionais? (Arq., p.67-8)

\section{A FORMAÇÃO DOS CONCEITOS}

Considerando que os conceitos aparecem numa dispersão, aparentemente em desordem, é necessário que sejam descritos e organizados no campo dos enunciados, a fim de estabelecer como sucedem e como coexistem.

\section{Formas de sucessão}

Ordem das séries enunciativas: incluem as ordens das inferências, das implicações sucessivas, dos raciocínios demonstrativos, das ordens das descrições, dos esquemas de generalização, de especificação progressiva, da ordem da narrativa etc.

Tipos de dependência dos enunciados: dependência hipótese-verificação, asserção-crítica, lei geral-aplicação particular.

Esquemas retóricos: segundo os quais pode-se combinar grupos de enunciados: como se encadeiam as descrições, deduções, definições, cuja seqüência caracteriza a arquitetura do texto.

\section{Formas de coexistência}

Campo de presença: pela análise dos enunciados já formulados e que são retomados a título de verdade admitida, descrição exata, raciocínio fundado, pressuposto necessário, crítica, discussão e julgamento.

Campo de concomitância: trata-se dos enunciados que concernem a domínios de objetos inteiramente diferentes e que pertencem a tipos de discursos totalmente diversos, mas que atuam entre os enunciados estudados (Arq., p.73). Podem ser: aqueles que servem de confirmação analógica, de princípio geral e de premissas aceitas para um raciocínio, de modelos que podemos transferir para outros conteúdos, que funcionam como instância superior, que não são mais nem admitidos nem discutidos, mas em relação aos quais se estabelecem relações de filiação, gênese, transformação, continuidade, descontinuidade histórica (domínio da memória).

\section{Procedimentos de intervenção}

Não são os mesmos para todas as formações e podem aparecer nas técnicas de reescritura, nos métodos de transcrição; nos modos de tradução dos enunciados quantitativos para qualitativos e vice-versa; nos meios

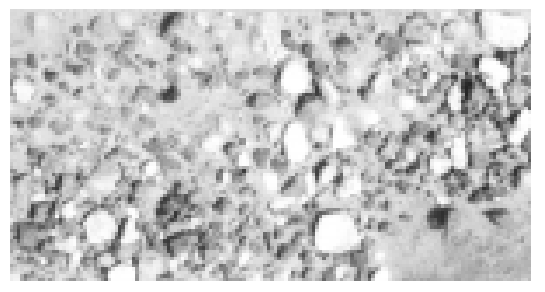


utilizados para aproximação dos enunciados, para refinar sua exatidão; na delimitação; na transferência; na sistematização; na redistribuição dos enunciados (Arq., p.73-4). Neste momento é possível, segundo Foucault, descrever "... a dispersão anônima (dos enunciados) através de textos, livros e obras", segundo "... um anonimato uniforme. a todos os indivíduos que tentam falar neste campo discursivo" (Arq., p.75-7).

\section{A FORMAÇÃO DAS ESTRATÉGIAS}

Para o autor, os discursos se organizam em conceitos, objetos, enunciações, segundo determinadas "estratégias", difíceis de serem detalhadas. Depreende-se que para formação discursiva há diferentes possibilidades estratégicas. Foucault indicou as seguintes direções da pesquisa (Arq., p.82-4):

determinar os pontos de difração possíveis do discurso: pontos de incompatibilidade, de equivalência, de junção de uma sistematização;

estudar a economia da constelação discursiva: a relação do discurso com aqueles que lhe são contemporâneos ou vizinhos, a fim de estabelecer analogias, oposições, complementaridades, singularidades.

estabelecer a função que deve exercer o discurso em um campo de práticas não discursivas quanto a: relações sociais (nas práticas, nas decisões políticas, nas práticas cotidianas); regimes e processos de apropriação do discurso (grupos sociais), posições possíveis do desejo em relação ao discurso (elemento de simbolização).

SABER

"A este conjunto de elementos, formados de maneira regular por uma prática discursiva e que são indispensáveis à constituição de uma ciência, apesar de não se destinarem necessariamente a lhe dar lugar, pode-se chamar saber" (Arq., p.222).

LIMIARES

Uma formação discursiva pode apresentar emergências distintas:

Limiar de positividade: "O momento a partir do qual uma prática discursiva se individualiza e assume sua autonomia, o momento, por conseguinte, em que se encontra um único e mesmo sistema de formação dos enunciados, ou, ainda, o momento em que esse sistema se transforma" (Arq., p.225).

Limiar de epistemologização: "Quando no jogo de uma formação discursiva, um conjunto de enunciados se recorta, pretende fazer valer (mesmo sem consegui-lo) normas de verificação e de coerência e exerce, face ao saber, uma função dominante (de modelo, de crítica ou de verificação)" (Arq., p.226).

Limiar de cientificidade: "Quando a figura, epistemologicamente assim delineada, obedece a um certo número de critérios formais, quando seus enunciados não obedecem somente a regras arqueológicas de formação, mas, além disso, obedecem a certas leis de construção das proposições" (Arq., p.226).

Limiar de formalização: "Quando esse discurso científico, por sua vez, 
puder definir os axiomas que the são necessários, os elementos que usa, as estruturas proposicionais que lhe são legitimas e as transformações que aceita, quando puder, assim, desenvolver, a partir de si, o edifício formal em que se constitui" (Arq., p.226).

Para Foucault, a repartição desses limiares constitui para a Arqueologia um dos seus domínios maiores de exploração.

\section{Considerações finais}

Certamente, o corpo conceitual da Arqueologia é maior do que o aqui exposto, e o pesquisador, necessariamente, deverá não somente ir ao original completo do texto de onde foram retirados, mas ler as obras que o utilizaram. As pesquisas empíricas empreendidas por Foucault são os documentos básicos que fornecem ao leitor a possibilidade de visualizar como o autor tenta

medir as mutações que se operam em geral no domínio da história, empresa onde são postos em questão os métodos, os limites, os temas próprios à história das idéias, empresa pela qual se tenta aí desfazer as últimas sujeições antropológicas; empresa que quer em troca mostrar como essas sujeições puderam se formar. (Arq., p.24)

Ao relacionarmos os conceitos que fundamentam a metodologia da Arqueologia, a intenção foi a de fornecer, como o título do trabalho enuncia, um guia/vocabulário, assumindo que esta metodologia oferece enormes possibilidades para a pesquisa que se volte para a análise das formações discursivas. Mesmo aqueles que foram extremamente críticos em relação a Foucault, como é o caso de Rabinow \& Dreyfuss (1995, p.114), reconhecem que "Ele tentou tornar a história das ciências humanas inteligivel em termos de regras que, desconhecidas pelos atores envolvidos, regularam e governaram todos os atos discursivos sérios". Essa tentativa de "revelação" é que leva o arqueólogo a descrever, em termos teóricos, as regras que regem as práticas discursivas. Como também inferem esses autores (1995, p.114), "Colocando a verdade e a seriedade entre parênteses, o arqueólogo opera num nível que é livre das influências das teorias e das práticas que estuda". Rabinow \& Dreyfuss lembram-nos que, nos trabalhos que se seguem à Arqueologia do Saber, "a prática é considerada mais fundamental que a teoria". Também assinalam que "O investigador não é mais o espectador desligado dos monumentos discursivos mudos. Foucault compreende e tematiza o fato de que ele mesmo, como qualquer outro investigador, está envolvido nas práticas sociais que analisa e é, em parte, por elas produzido" (1995, p.115). Nesse momento, e após sua aula inaugural no Collège de France, pronunciada em 1970, que ele denominou L'ordre du discours (1971), abre-se uma nova fase nas pesquisas de Foucault - a da história genealógica. Agora, trata-se de introduzir a genealogia como "um método de diagnosticar e compreender o significado das práticas sociais a partir de seu próprio interior" (Rabinow \& Dreyfuss, 1995, p.115).

Inegavelmente, a metodologia da história arqueológica viria a constituir 
poderoso instrumento para inúmeras pesquisas. Sem pretender ser exaustivo, lembraríamos, no Brasil, a tese de doutorado de Arouca (1975), estudando a formação discursiva que se elabora sobre a Medicina Preventiva, trabalho no qual associa à perspectiva metodológica foucaultiana a formulação teórica materialista na vertente althusseriana; Machado e colaboradores (1978), sobre a emergência da Medicina Social e a constituição da psiquiatria no Brasil; Ferreira (1992), sobre o discurso da participação em saúde; Lacaz (1996) sobre a formação discursiva da Saúde do Trabalhador, associando à história aqueológica a história genealógica; Botazzo (1998) sobre a emergência da clínica odontológica; Ayres (1993), sobre a constituição histórica do objeto da Epidemiologia.

Consideramos, como aponta Ternes (1995), que a volta aos textos da primeira fase de Foucault "significa vencer um certo modismo que a difusão da genealogia do poder suscitou no universo acadêmico". Quanto ao potencial metodológico derivado da perspectiva da análise do discurso, a filósofa Vera Portocarrero diz que a Arqueologia responde à questão "como"?, os saberes emergem e se transformam, e a genealogia. Completando esta análise, tenta responder à questão do "porque" dos saberes. Se, no primeiro momento, procura-se articular as interrelações discursivas com as práticas institucionais, no segundo, a "origem" dos saberes é situada no plano das relações de poder (Portocarrero, 1994, p.53).

Mas, deixemos a palavra final ao próprio Foucault, quando não somente retoma sua preocupação com os motivos que o levaram a escrever, mas fornece ao investigador um alento frente àquela formação discursiva que ele quer conhecer. Escreve o filósofo:

$$
\begin{aligned}
& \text { um tanto cegamente, e por meio de fragmentos sucessivos e diferentes, } \\
& \text { eu me conduzi nessa empreitada de uma história da verdade: analisar, } \\
& \text { não os comportamentos, nem as idéias, não as sociedades, nem suas } \\
& \text { "ideologias”, mas as problematizações das quais o ser se dá como } \\
& \text { podendo e devendo ser pensado, e as práticas a partir das quais essas } \\
& \text { problematizações se formam”. A dimensão arqueológica da análise } \\
& \text { permite analisar as próprias formas da problematização; a dimensão } \\
& \text { genealógica, sua formação a partir das práticas e suas modificações. } \\
& \text { (Foucault, 1984, p.15) (grifos do autor) }
\end{aligned}
$$

\section{Referências}

ALMEIDA, A. J. A proposta de "pensar diferente" em Foucault. Escritos, n.1, p.97-106, 1994.

AROUCA, A. S. S. O dilema preventivista: contribuição para a comprensão e crítica da Medicina

Preventiva. Campinas, 1975. Tese (Doutorado) Faculdade de Ciências Médicas, Universidade Estadual de Campinas.

AYRES, J. R. C. M. Objeto da Epidemiologia e nós. Physis, v.3, n.1, p.55-76, 1993.

BOTAZZO, C. Da arte dentária: um estudo arqueológico sobre a prática dos dentistas. Campinas, 1998.

Tese (Doutorado). Faculdade de Ciências Médicas, Universidade Estadual de Campinas.

ERIBON, D. Michel Foucault: 1926-1984. Trad. H. Feist. São Paulo: Companhia das Letras, 1990.

FERREIRA, M. A . F. Entre a norma institucional e a ação coletiva: uma Arqueologia da participação 
popular em saúde. Campinas, 1992. Tese (Doutorado). Faculdade de Ciências Médicas, Universidade Estadual de Campinas.

FOUCAULT, M. Folie e déraison. Histoire de la folie à l'âge classique. Paris: Plon, 1961. Edição Brasileira.

História da Loucura. São Paulo: Perspectiva, 1978.

FOUCAULT, M. Naissance de la clinique. Une archéologie du regard médical. Paris: Puf, 1963. Edição

Brasileira. O nascimento da clínica. Rio de Janeiro: Forense Universitária, 1977.

FOUCAULT, M. Les mots et les choses. Une archéologie des sciences humaines. Paris: Gallimard, 1966.

Edição Brasileira. As palavras e as coisas. Uma arqueologia das ciências humanas. São Paulo:

Martins Fontes, 1990.

FOUCAULT, M. L’archéologie du savoir. Paris: Gallimard, 1969. Edição Brasileira. A arqueologia do

saber. Petrópolis: Vozes, Lisboa: Centro do Livro Brasileiro, 1972.

FOUCAULT, M. História da sexualidade 2: o uso dos prazeres. Trad. M.T.C. Albuquerque. Rio de Janeiro:

Graal, 1984.

LACAZ, F. A . C. Saúde dos Trabalhadores: um estudo sobre as formações discursivas daa academia, dos serviços e do movimento sindical. Campinas, 1996. Tese (Doutorado) Faculdade de Ciências

Médicas, Universidade Estadual de Campinas.

MACHADO, R. Ciência e saber: a trajetória da arqueologia de Michel Foucault. Rio de Janeiro: Graal, 1981.

MACHADO, R., LOUREIRO, A., LUZ, R., MURICY, K. Danação da norma: Medicina Social e constituição da Psiquiatria no Brasil. Rio de Janeiro: Graal, 1978.

PORTOCARRERO, V. História dos saberes e das práticas. In: (org.) Filosofia, História e

Sociologia das Ciências: abordagens contemporâneas. Rio de Janeiro: Fiocruz, 1994.

RABINOW, P., DREYFUSS, H. Michel Foucault: uma trajetória filosófica - para além do estruturalismo e

da hermenêutica. Trad. V. Portocarrero. Rio de Janeiro: Forense Universitária, 1995.

TERNES, J. M. Michel Foucault e o nascimento da modernidade. Tempo Social. Rev. Sociol. USP, v.7,

n.1-2, p.45-52, 1995.
